\title{
The Effect of Academic Achievement and Learning Strategies on Self-Efficacy of the Third Grade High School Female Student (Case Study: The Education Office, District One, Kerman)
}

Seyedeh Khadijeh Mousavi

A Graduate Student in Education Management at Qeshm International Branch, Islamic Azad University

Mahnoosh Abedini (PhD)

Assistant Professor of Farhangian University Hormozgan, Bandar Abbas, Iran

\author{
Doi:10.5901/mjss.2016.v7n2s2p241
}

\section{Abstract}

\begin{abstract}
Achievement motivation is influenced by various factors, including the environmental incentives, individual dispositions, ambition, and learning capacity, especially the student's self-efficacy, as well as the student's acquired knowledge of selfregulation. In the present research, the relationship of three learning strategies, self-efficacy, and achievement motivation is investigated, adopting a correlational, descriptive design. The statistical population included 256 high school female third graders within the administrative district 1 of the Kerman Education Office from September 2014 to April 2015. The data were gathered from a standardized questionnaire. The theoretical model significance and fitness was verified using the procedures in the SPSS software. For data analysis, correlation tests and linear regression were performed. The results, in the first place, confirmed the model significance and applicability. According to the results of the data analysis, academic achievement motivation and learning strategies had positive effect on self-efficacy of the female third graders.
\end{abstract}

Keywords: academic achievement, self-efficacy, learning strategies

\section{Introduction}

Academic achievement and its determinants have been for years of central interest to educational psychologists and other educational experts. In recent years, the experts and scholars of the field have been shifting their attention from the behavioral factors towards a variety of cognitive determinants, including attribution, cognitive and metacognitive strategies, or emotional states accompanied with cognitions, the self-system, and self-assessment (Mir Moshtaghi, 2005).

Academic achievement motivation is one of the requirements for learning and it is something that intensifies behavior and gives it direction, and helps the learner with maintenance of the so acquired behavior. With this motivation, people have the necessary mobility for successfully completing an assignment, or keeping on an activity until a certain level of competency in their work is attained in order to eventually succeed in learning and realizing the academic progress (Mohammadi, 2006).

Learning strategies have a simple structure by using which the learners would be able to learn the educational materials more quickly, understand them better, and more importantly, to memorize it for a longer period of time. The learners, applying the learning strategies, will actively engage in learning process, will link new materials with their earlier information, and will constantly monitor their learning process.

The purpose of this study is to see if academic achievement motivation and learning strategies do actually affect self-efficacy among the understudy female third graders. The remainder of this paper is organized as follows. The next section presents the research problem statement and justifies conduction of the current research conduction in terms of significance and necessity. Next, the research theoretical background is reviewed and the key concepts are described. The research hypotheses in light of a conceptual model are subsequently presented. Research methodology is discussed next followed by data analysis and test of the hypotheses whereby the key findings are highlighted. Finally, the research is concluded by a number of suggestions made to future researchers. 


\section{Problem Statement}

Academic achievement and the factors associated to it have been for years of interest to education experts and scholars and account for a large share of the researches (Amini, 2003). As knowledgeable, productive and creative people are indispensible for growth and prosperity of each society, nurture and development of achievement motivation invigorates behavior and gives direction to people's behavior, interests, and needs (Tamannayee Far and Gandomi, 2011).

Achievement motivation is considered a significant variable in academic and job-related topics. Scholars have pointed out that the relationships between achievement motivation and many other principal constructs (e.g. learning, acceptance, and performance) have still remained ambiguous. In some instances, there are contradictory findings on the relationship of achievement motivation with learning. One reason for this confusion could be the wide variety of the conceptual and operational definitions applied by researchers of achievement motivation, indicating wide divergence in conceptualization and measurement of achievement motivation (Woo et al, 2008).

Self-efficacy is derived from the Bandura's Cognitive-Social Theory and refers to individual's beliefs or judgments regarding one's own abilities to perform the assigned tasks and fulfill one's responsibilities. In his view, self-efficacy is people's beliefs and judgments regarding their abilities in carrying out specific assignments in particular situations (Touzendejani et al, 2011).

Considering the above arguments emphasizing the importance of certain educational variables, this research attempts to find out about the possible impact of academic achievement motivation and learning strategies on selfefficacy amongst a number of the provincial female high school students within the District 1 of the Kerman Education Office.

\section{Research Justification}

The issue of success or failure in study is among the most important concerns of each education system. Academic success and achievement in every society represents accomplishment of the education system in targeting the right objectives and paying due attention to gratification of individual needs (Tamannayee Far and Gandomi, 2011). Therefore, an education system is considered efficient only when academic achievement of its students at all levels is the greatest and the highest. Achievement motivation which was initially introduced by Murray (1938) as the "need for achievement" is one of the most important acquired incentives in any individual (Liem et al, 2007).

Recently, the researchers have started developing multi-facet measures of motivation, emphasizing it as a quality or attribute. The most important of these measures are the Questionnaire of Achievement Motivation Determinants, the World of Work or Career Assessment Instrument, and the Achievement Motivation Scale. From among these measures, the achievement motivation scale has been the most comprehensive one so far. The achievement motivation scale consists of 17 subscales or components which are categorized into three empirically derived factors, indicating the measurement equivalence among several cultures. Such multi-facet achievement measures would help resolving the inconsistencies which existed in the prior research. There is a growing body of evidence indicating the complex and multidimensional structure of achievement motivation which calls for some in depth research of its different layers (Woo et al, 2008).

Researchers have shown those who have a high achievement motivation want to become perfect, and to improve their performance. They are dutiful and conscientious and prefer to engage in activities that are challenging, and would rather undertake a job in which their success could be assessed quite reliably. Having a high achievement motivation enables one to make maximum use of one's capacity for achieving the goal following which to attain a high degree of self-efficacy. Obviously, the same dynamic interaction exists between subsets of self-efficacy and achievement motivation. That is to say, when one does not fear failure, plans how to achieve the goal, in drawing the plans, takes one's ability into account (self-assessment, according to the previously made preparations, he expects to succeed (selfbelief), and finally, through step-by-step control of his behavior he governs his behavior.

In this regard, identification of the contributing factors to academic motivation in conjunction with learning strategies would significantly help improving academic performance of people. In the prior research literature of our society, studies on academic motivation, especially with regard to self-efficacy and learning of school and college students, are missing, since this topic has not been yet specifically and systematically addressed which confirms the novelty of the under study subject. In learning process, the careful monitoring of the learning process by the learner himself/herself makes him/her an increasingly self-reliant and efficient learner, creating the necessary motivation through such process (Liem et al, 2008).

In this study, the researcher is focused on a specific research domain, namely achievement motivation, and 
examines to find out if a multifaceted measurement of achievement motivation can be used for explanation and resolution of the contradictions in the existing writings or not.

The issue of achievement motivation has been extensively explored however the aspects on which the present research is focused have not been adequately addressed in prior works. In most of these researches, achievement motivation was studied as a multidimensional construct. This explains, to some extent, the contradictory findings noted above. Some of the achievement motivation practices can be augmented by self-efficacy and learning skills.

This research also attempted to examine the effectiveness of learning strategies in academic achievement and find out whether the students who make use of self-regulation strategies, enthusiasm, and skills in learning process will have a higher academic performance or not.

\section{Research Hypotheses}

In the present research, the following general hypotheses are made:

Main hypothesis: academic achievement motivation and learning strategies have positive effect on self-efficacy of the high school female third graders in District 1 of the Kerman Education Office.

By allowing for the individual effect of the independent variables, the above main hypothesis is decomposed into two sub-hypotheses as follows:

Sub-hypothesis 1: academic achievement motivation has positive effect on self-efficacy of the female third graders of the understudy education office.

Sub-hypothesis 2: learning strategies has positive effect on self-efficacy of the female third graders in the understudy education office.

\section{Methodology}

Present research is conducted, using a descriptive, correlational design. It is descriptive in that it systematically and accurately describes the topic of interest as it is in reality. It is also correlational (causal), since it using correlation analysis examines the amount of change in one factor as a result of a change in another (other) factor(s). In this type of researches, relationships on the surface are paid attention to, and the causal reasons underlying the correlation are not necessarily probed into.

The statistical population in the present research included all the high school female third graders (256, in total) within District 1 of the Education Office of Kerman city. Data analysis consisted of "descriptive statistics" and "inferential statistics".

At this stage of the data analysis, general characteristics of the collected data are calculated and expressed in terms of measure of central tendency (mean) and measures of variation (standard deviation and variance).

Independence of the error terms was verified by Durbin-Watson test, and the relationships between the variables were examined using multiple, linear regression model and Pearson correlation test.

\section{Results}

The results on test of the main hypothesis: the results indicated positive relationship of academic achievement motivation and learning strategies with self-efficacy of the female third graders. The correlation coefficient $(R=0.797)$ signifies a very strong positive correlation which is significant at 95 percent confidence (since the obtained Sig. level 0,000 is smaller than the predefined significance level 0.05). In addition, from the obtained regression coefficient, it can be inferred that one unit increase in the student's academic achievement motivation and learning strategies will raise self-efficacy for 0.166 and 0.658 , respectively. The research results confirmed significance of the impact the academic achievement and learning strategies would have on the student's self-efficacy, implying that any increase or decrease in the level of academic achievement motivation and learning strategies is accompanied with an increase or decrease in self-efficacy, accordingly.

The results on test of the sub-hypothesis 1: a positive association is assumed between academic achievement motivation and self-efficacy of the understudy high school female third graders.

The results indicated a positive relationship between academic achievement motivation and self-efficacy of the female students. From the correlation coefficient $(R=0.791)$, a very strong positive correlation is inferred which is significant at 95 percent confidence (since the obtained Sig. level 0,000 is smaller than the predefined significance level 0.05). In addition, the obtained regression coefficient implies that one unit increase in the student's academic 
achievement motivation will raise self-efficacy for 0.791 . The research results confirmed significance of the impact the academic achievement might have on the student's self-efficacy.

The results on test of the sub-hypothesis 2: a positive association is assumed between learning strategies and selfefficacy of the understudy high school female third graders.

The results indicated a positive relationship between academic achievement motivation and self-efficacy of the female students. The correlation coefficient $(R=0.692)$ implies a very strong positive correlation which is significant at 95 percent confidence (since the obtained Sig. level 0,000 is smaller than the predefined significance level 0.05 ). In addition, the obtained regression coefficient implies that one unit increase in the student's academic achievement motivation will raise self-efficacy for 0.692 .

From the results, it can be inferred that self-efficacy is of influence in development and improvement of learning strategies. Present research showed that learning strategies of skilled, enthusiast, and self-regulated students are capable and efficient.

\section{Suggestions to Future Researchers}

1. Similar researches can be conducted in non-profit, private schools and public schools.

2. In future researches, the effect of other learning methods and academic achievement motivation to be measured as well.

3. Similar researches are expected to be conducted for other educational levels.

4. Assessing generalizability and applicability of the obtained findings from this study to a broader temporal and spatial scope.

5. Conduction of similar research by applying other research methods, including qualitative methods.

\section{Refrences}

Abbassian Fard, Mehrnoush and Bahrami, Hadi (2010), "Self-Efficacy and Achievement Motivation," Roshd Magazine, 6(1): 3-7

Amini, Shahriar (2033), "The Role of Self-Efficacy, Self-Regulation, and Self-Esteem in academic achievement of High School Third Grade Students of Natural Sciences in Shahr-e Kord," Master's Thesis, Department of Psychology, Faculty of Education Sciences and Psychology, Teacher Training University, Tehran

Bakhshi, Mahmoud and Ahanchian, Mohammad Reza (2003), "The Academic Achievement Prediction Model: The Role of Critical Thinking and Academic Learning Self-Regulation Strategies of Nursing Students," The Iranian Journal of Education in Medical Sciences, 13(2): 153-163

Hejazi, Elaheh and Naghsh, Zahra (2008), "The Structural Model of the Relationships Among Perception of Class Structure, Achievement Goals, Self-Efficacy, and Self-Regulation in the Subject Matter Mathematics," New Findings of Cognitive Sciences, 10(4): 27-38

Karamati, Hadi (2001), "The Relationship of Perceived Self-Efficacy of the Third Grade Middle School Students and their Attitude to Subject Matter Mathematics with their Achievement," Master's Thesis in Psychology, Tehran: Faculty of Education Sciences and Psychology, Teacher Training University

Karimzadeh, Mansoureh and Mohseni, Niek Chehreh (2005), "The Relationship of Academic Self-Efficacy with Academic Achievement in High School Female Second Graders of Tehran," Quarterly Journal of Women, 4(2): 11

Kim, R. H. (2010), "Self-Directed Learning Management System: Enabling Competency and Self-Efficacy in Online Learning Environments," Dissertation, California, 1-117

Kosnin A.M. (2007), "Self-Regulated Learning and Academic Achievement in Malaysian Undergraduates," International Education Journal, 8(1): 221-8

Lee. J.K. (2008), "The Effects of Self-Regulated Learning Strategies and System Satisfaction Regarding Learners performance," Information and Management, 40.pp.133-140

Mir Moshtaghi, Shahrbanu (2005), "A Comparative Study of the Relationship of Self-Efficacy and Self-Regulation with Academic Achievement of the High School Third Grade Female Students of Human Sciences and Exact Sciences (Mathematics and Physics) within City of Tehran," Master's Thesis in Education Sciences, Faculty of Education Sciences and Psychology, Al Zahra University

Murray, H.A. (1938), "Explorations in Personality," New York: Oxford University Press

Liem, Arief Darmanegara, Lau, Shun, and Nie, Youyan (2007), The Role of Self-Efficacy, Task Value, and Achievement Goals in Predicting Learning Strategies, Task Disengagement, Peer Relationship, and Achievement Outcome, Contemporary Educational Psychology, 33: 486-512

Roberts, B. W., Chernyshenko, O. S., Stark, S., \& Goldberg, L. R. (2005), "The Structure of Conscientiousness: An Empirical Investigation based on Seven Major Personality Questionnaires," Personnel Psychology, 58, 103-139

Sabuteh, Elaheh (2010), "The Relationship of Academic Self-Concept and Achievement Motivation with Academic Achievement of the 
High School Female Third Graders in Zone 18 of Tehran," Master's Thesis, Faculty of Psychology and Education Sciences, Semnan Branch, Islamic Azad University

Salehi, Mohammad and Enayati, Taraneh (2009), "The Relationship of The Main Constituents of Study and Learning Strategies with Academic Achievement of the Students at Mazandaran Islamic Azad University," Quarterly Journal of New Approach in Educational Management, Marvdasht Branch, Islamic Azad University, 2(3): 145-162

Tamanayee Far, Mohammad Reza and Gandomi, Zeinab (2011), "The Relationship of Achievement Motivation with Academic Achievement in Students," Quarterly Journal of Education Strategies, 4(1): 15-19

Tozandeh Jani, Tavakkol Zadeh, Jahanshir, and Lagzian, Zahra (2011), "Effectiveness of Parental Styles in Self-Efficacy and Mental Health of Human Sciences Students at Payam-e-Nour University and Islamic Azad University of Neishabour," Ofogh-e-Danesh; Quarterly Journal of the University of Medical Sciences and Health Services, Gonabad, Period 17, N0.2

Vrugt A. and Oort, F.J. (2008), "Metacognition, Achievement Goals, Study Strategies and Academic Achievement: Pathways to Achievement," Metacognition and Learning, 3(2): 123-46

Woo, Sang Eun, Gibbons, Alyssa Mitchell, and George C. Thornton (2007), "Latent Mean Differences in The Facets of Achievement Motivation of Undergraduate Students and Adult Workers in the US," Personality and Individual Differences, 43: 1687-1697 